\title{
Solvent effects in the synthesis of CoB catalysts on hydrogen generation from hydrolysis of sodium borohydride
}

\author{
SHEN Xiaochen, DAI Min, GAO Ming, ZHAO Bin*, DING Weiping \\ Key Laboratory of Mesoscopic Chemistry of Ministry of Education, School of Chemistry and Chemical Engineering, Nanjing University, Nanjing 210093, \\ Jiangsu, China
}

\section{A R T I C L E I N F O}

Article history:

Received 11 January 2013

Accepted 8 March 2013

Published 20 May 2013

\section{Keywords:}

Sodium borohydride

Hydrolysis

Hydrogen generation

Cobalt boride

Non-crystalline structure

Solvent effect

\begin{abstract}
A B S T R A C T
Solvent effects are important in synthetic chemistry, especially in preparing nanosized materials in solution. The sizes, morphologies, and properties of nanoparticles obtained from solution are greatly influenced by the solvents used. CoB catalysts were synthesized in solvents with different viscosity and polarity, including water, methanol, ethanol, and $n$-propanol. Solvent effects on the size and morphology of CoB were investigated using X-ray diffraction, field emission scanning electron microscopy, transmission electron microscopy, X-ray photoelectron spectroscopy (XPS), and nitrogen sorption measurements. $\mathrm{CoB}$ catalysts possessed non-crystalline structures composed of discrete nanoparticles, but became more agglomerated with increasing solvent viscosity. The hydrolysis of $\mathrm{NaBH}_{4}$ showed that catalyst morphology and texture greatly affected catalytic activity. XPS showed that Co and B were each present in elemental and oxidized states in the CoB catalysts, and that the $\mathrm{Co} / \mathrm{B}$ surface ratio varied greatly with a higher $\mathrm{Co} / \mathrm{B}$ ratio resulting in better catalytic properties. Solvent effects were analyzed in terms of steric hindrance and viscosity, and a mechanism for CoB synthesis in the different solvents was proposed.
\end{abstract}

(C) 2013, Dalian Institute of Chemical Physics, Chinese Academy of Sciences. Published by Elsevier B.V. All rights reserved.

\section{Introduction}

As a renewable energy source, hydrogen possesses many advantages over traditional fuels, including higher energy density and zero emissions [1,2]. Developing effective safe hydrogen storage materials is a crucial challenge in realizing a hydrogen economy [3]. Reversible hydrogen storage materials such as metal/alloy hydrides [4-6], carbon materials [7], and complex hydrides [8-10] have greater promise than traditional pressurized tanks and cryogenic liquid hydrogen, owing to their high volumetric hydrogen capacity, favorable energy efficiency, and safety. Sodium borohydride $\left(\mathrm{NaBH}_{4}\right)$ is among the chemical hydrides of interest, because of its high hydrogen capacity (theoretical value of 10.8 wt\%), good storability and reaction controllability, low reaction-initiating temperature, and environmentally benign hydrolysis products [11,12]. $\mathrm{NaBH}_{4}$ is hydrolyzed according to:

$\mathrm{NaBH}_{4}+2 \mathrm{H}_{2} \mathrm{O} \rightarrow \mathrm{NaBO}_{2}+4 \mathrm{H}_{2} \uparrow \Delta H^{\theta}=-216.7 \mathrm{~kJ} / \mathrm{mol}$

To suppress the self-hydrolysis of $\mathrm{NaBH}_{4}, \mathrm{NaOH}$ is often added with the $\mathrm{NaBH}_{4}$ solution as a stabilizer. The hydrolysis reaction can also be greatly accelerated at ambient temperature using catalysts [13]. Numerous catalysts based on metals/alloys have been reported, including Pt [14-16], Raney Ni and Co [17], and Co and Ni borides [18-20]. Co and Ni based catalysts are particularly attractive because of their relatively high catalytic activity, low cost, widespread availability, and

\footnotetext{
* Corresponding author. Tel: +86-25-83592304; Fax: +86-25-83317761; E-mail: binzhao@nju.edu.cn This work was supported by the Nature Science Foundation of Jiangsu Province (BK2010387), the National Natural Science Foundation of China (41172239), and the Fundamental Research Funds for the Central Universities (1118020513, 1106020513). 
ease of preparation.

Metal borides including $\mathrm{CoB}, \mathrm{NiB}, \mathrm{NiCoB}$, and RuB are common catalysts in selective hydrogenation and hydrogen generation, and exhibit favorable activities and/or selectivity in these reactions. Our group reported the synthesis of metal boride ultrafine particles $(\mathrm{CoB}$ and $\mathrm{NiB})$ and nanotubes $(\mathrm{NiB}, \mathrm{FeB}$, $\mathrm{NiPB}, \mathrm{NiCuB}$, and $\mathrm{NiFeB}$ ), and their catalytic properties were investigated [21-23]. Such catalysts are generally synthesized by chemical reduction and possess non-crystalline structures [18,24-28]. Their catalytic properties are closely related to their specific non-crystalline structure, which imparts short-range order and long-range disorder, and unsaturated surface sites. A lot of work on electron effects and the catalytic properties of non-crystalline structured materials have been done by Fan's and Deng's research groups [29,30]. Industrial applications of non-crystalline catalysts were reported by Min et al. [31,32]. Non-crystalline catalysts are sensitive to synthesis reaction conditions including concentration, stirring rate, temperature, and solvent [19,33,34]. Liu et al. [35] studied non-crystalline Ni-P-B catalysts for the selective hydrogenation of $p$-chloronitrobenzene, and found that the reaction medium was important, e.g., catalytic performance was higher in methanol than in ethanol. Fan et al. [36] investigated $\mathrm{Ru}-\mathrm{B} / \mathrm{TiO}_{2}$ catalysts for the hydrogenation of ethyl lactate to 1,2-propanediol under mild conditions $\left(90^{\circ} \mathrm{C}, 4 \mathrm{MPa}\right)$ and reported that an aqueous reaction medium significantly enhanced catalytic performance. Similar results were reported by Ning et al. [37] and Liu et al. [38].

Solvent effects are important in both the catalytic reaction and solution preparation of catalysts. Sizes and morphologies, and thus properties of catalysts synthesized in solution, are heavily influenced by solvents, and to date little work on this issue has been reported. In the current study, $\mathrm{CoB}$ catalysts were synthesized in solvents with differing polarity and viscosity including water, methanol, ethanol, and $n$-propanol. The solvent effects on the size and morphology of CoB were investigated using X-ray diffraction (XRD), field emission scanning electron microscopy (FE-SEM), transmission electron microscopy (TEM), X-ray photoelectron spectroscopy (XPS), and nitrogen sorption measurements. The CoB synthesis mechanism in different solvents is discussed.

\section{Experimental}

\subsection{Catalyst preparation}

CoB catalysts were synthesized by chemical reduction. A typical synthesis procedure for $\mathrm{CoB}\left(\mathrm{H}_{2} \mathrm{O}\right)$ was as follows. Appropriate amounts of $\mathrm{Co}(\mathrm{Ac})_{2} \cdot 4 \mathrm{H}_{2} \mathrm{O}$ and $\mathrm{NaBH}_{4}$ were dissolved separately in $\mathrm{H}_{2} \mathrm{O}\left(\mathrm{NaBH}_{4}: \mathrm{Co}^{2+}=3: 1\right.$, molar ratio). The $\mathrm{NaBH}_{4}$ solution was added dropwise to the $\mathrm{Co}(\mathrm{Ac})_{2}$ solution under vigorous stirring. During the solution preparation and reduction, the solution vessels and reactor were placed in an ice-water bath to control the $\mathrm{NaBH}_{4}$ hydrolysis and maintain the reaction temperature to limit agglomeration of $\mathrm{CoB}$ nanoparticles. The black precipitate was separated by centrifugation, thoroughly washed with distilled water and absolute methanol, and dried under vacuum for $12 \mathrm{~h}$ at $323 \mathrm{~K}$. CoB synthesized in water was termed $\mathrm{CoB}\left(\mathrm{H}_{2} \mathrm{O}\right)$. $\mathrm{CoB}$ catalysts were also synthesized in absolute methanol, ethanol, and $n$-propanol using the same procedure, and were termed $\mathrm{CoB}(\mathrm{MeOH})$, $\mathrm{CoB}(\mathrm{EtOH})$, and $\mathrm{CoB}(\mathrm{PrOH})$, respectively.

\subsection{Catalyst characterization}

CoB morphology was studied using a JEOL JEM-1011 TEM $(100 \mathrm{kV})$ and a Hitachi S-4800 FE-SEM (10 kV). XRD patterns were recorded on a Philips X'pert diffractometer operated at 40 $\mathrm{kV}$ and $40 \mathrm{~mA}$ (Cu $K_{\alpha}$ radiation, $\lambda=0.154184 \mathrm{~nm}$ ). N 2 sorption isotherms were measured at $77 \mathrm{~K}$ on a Micromeritics ASAP 2030 system in static measurement mode. Samples were outgassed at $473 \mathrm{~K}$ for $6 \mathrm{~h}$ before sorption experiments. The pore size distribution was calculated by analyzing the isotherm adsorption branch using the BJH (Barrett-Joyner-Halenda) method. The bulk composition of catalysts was studied using inductively coupled plasma-atomic emission spectroscopy (ICP-AES), using a Perkin-Elmer Optima 5300 ICP-AES spectrometer. XPS was carried out using a PHI 5000 VersaProbe electron spectrometer, with an $\mathrm{Al} K_{\alpha}(h v=1486.6 \mathrm{eV})$ source. Binding energy (BE) values were calibrated using C $1 s=284.6$ $\mathrm{eV}$ as a reference. The coordination mode of $\mathrm{Co}^{2+}$ ions in different solvents was investigated using a Shimadzu UV-1800 UV-Vis absorption spectrometer, with a slit-width of $1.0 \mathrm{~nm}$ and scan range of 400-700 $\mathrm{nm}$.

\subsection{Catalytic activity experiments}

In a typical hydrogen generation experiment, $10.0 \mathrm{mg}$ of CoB catalyst in a sealed flask was placed in a thermostatic water bath maintained at $293.00 \pm 0.05 \mathrm{~K} .15 .00 \mathrm{ml}$ of $1 \mathrm{wt} \%$ $\mathrm{NaBH}_{4}$ aqueous solution (with $5 \mathrm{wt} \% \mathrm{NaOH}$ ) was added to the flask using a constant pressure funnel. The volume of $\mathrm{H}_{2}$ generated was measured from the water weight displaced from the sealed jar by a balance. The reaction time and corresponding weight of water were recorded, and the density of water at current temperature was used to convert the weight of water to volume of $\mathrm{H}_{2}$. Magnetic stirring at $800 \mathrm{r} / \mathrm{min}$ diminished the diffusion effect.

\section{Results and discussion}

\subsection{Catalytic properties of CoB catalysts synthesized in different solvents}

The catalytic properties of $\mathrm{CoB}$ were evaluated from the hydrolysis of $\mathrm{NaBH}_{4}$ at $293 \mathrm{~K}$. Alkaline $\mathrm{NaBH}_{4}$ solution is relatively stable with a half-life of $\sim 63 \mathrm{~d}$ at $\mathrm{pH} 13$ and a temperature of $293 \mathrm{~K}$. When catalyzed by $\mathrm{CoB}, \mathrm{NaBH}_{4}$ hydrolysis proceeds much faster. Figure 1(a) shows $\mathrm{H}_{2}$ generation with time for each of the four $\mathrm{CoB}$ catalysts, from which it is clear that catalysts synthesized in different solvents exhibited very different activities. Reaction rates were calculated from the linear regions of Fig. 1(a), and rates are compared in Fig. 1(b). Catalytic activities followed the order: $\mathrm{CoB}(\mathrm{MeOH})>\mathrm{CoB}\left(\mathrm{H}_{2} \mathrm{O}\right)>$ 

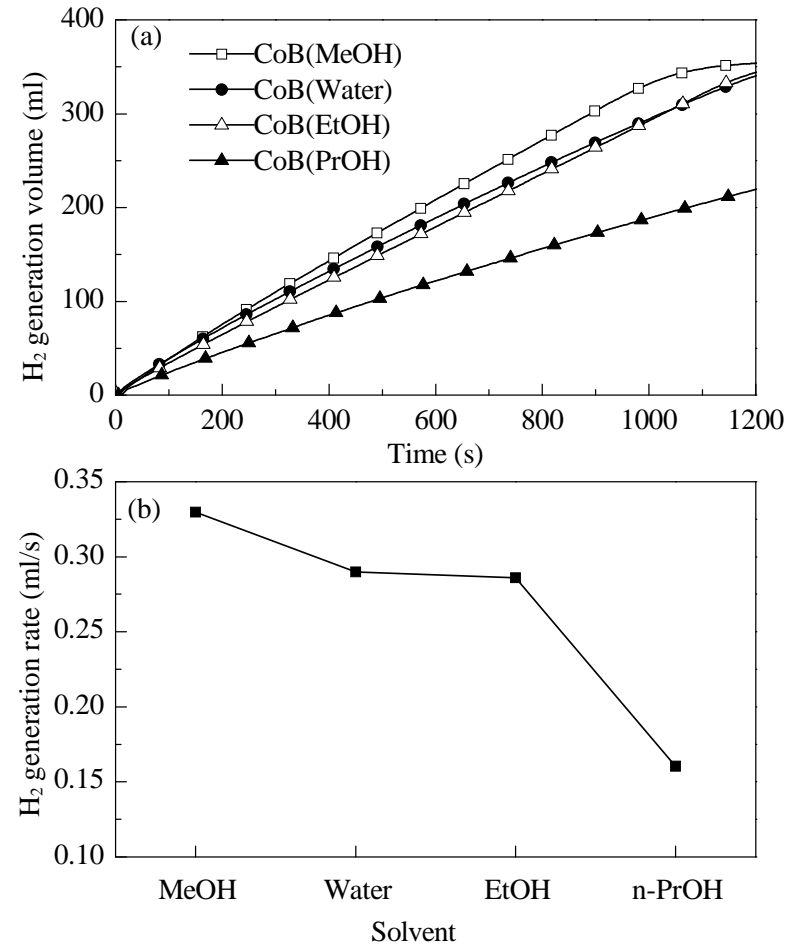

Fig. 1. Hydrogen generation rates of $\mathrm{CoB}$ catalysts synthesized in different solvents (a) and comparison of hydrogen generation rates of $\mathrm{CoB}$ catalysts synthesized in different solvents (b). Reaction conditions: 1 $w t \% \mathrm{NaBH}_{4}+5 \mathrm{wt} \% \mathrm{NaOH}$ aqueous solution, temperature $293.0 \mathrm{~K}$, amount of catalyst $10.0 \mathrm{mg}$.

$\mathrm{CoB}(\mathrm{EtOH})>\mathrm{CoB}(\mathrm{PrOH})$.

\subsection{Characterization of CoB catalysts synthesized in different} solvents

\subsubsection{XRD patterns}

The XRD patterns of CoB catalysts synthesized in different solvents are shown in Fig. 2, in which no diffraction peaks were observed. The CoB catalysts possessed non-crystalline structures which is consistent with the typical structures of $\mathrm{CoB}$ catalysts synthesized by chemical reduction at low temperature $[18,33]$.

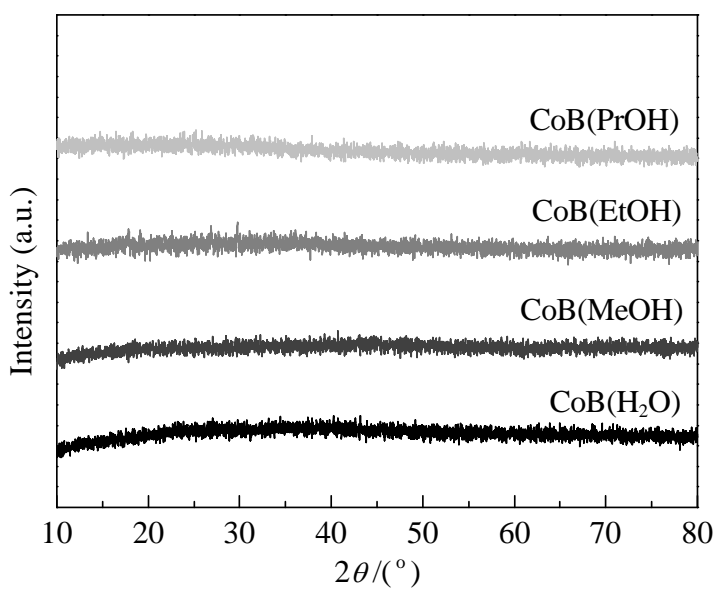

Fig. 2. XRD patterns of $\mathrm{CoB}$ catalysts synthesized in different solvents.
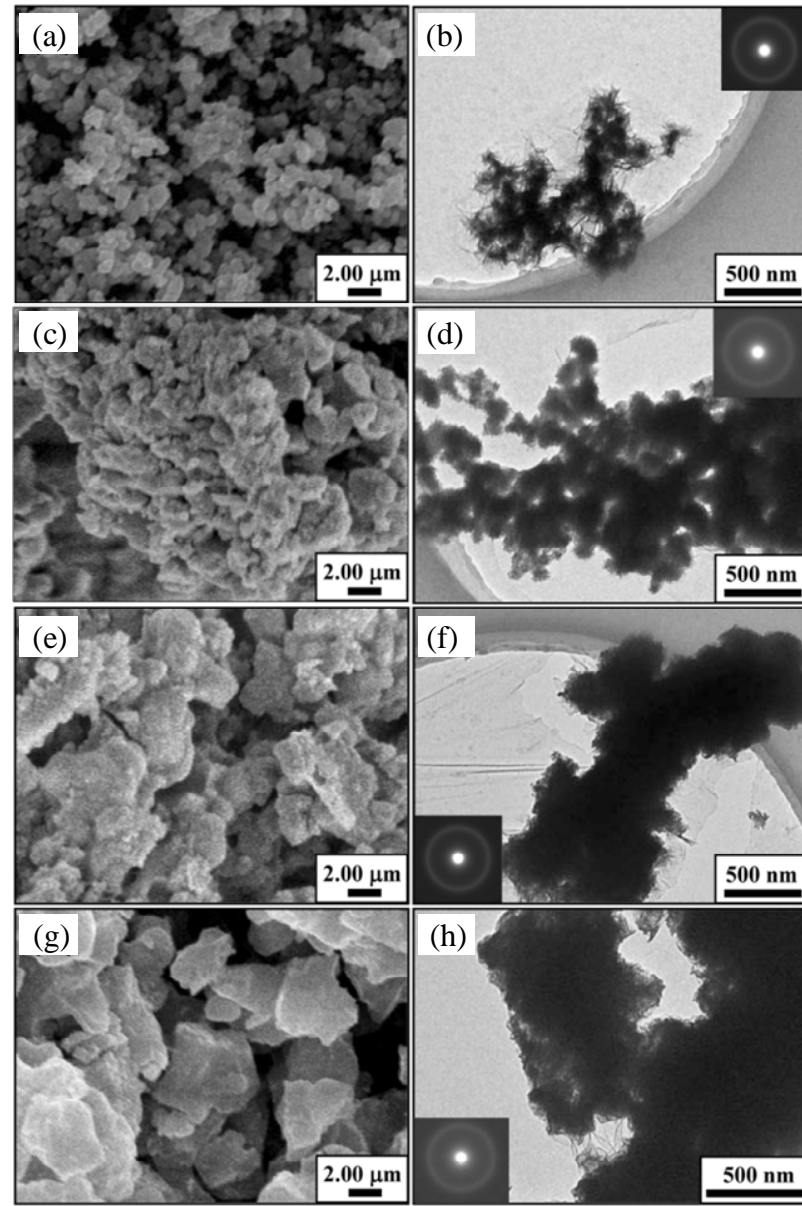

Fig. 3. SEM (a, c, e, g) and TEM (b, d, f, h) images of $\mathrm{CoB}\left(\mathrm{H}_{2} \mathrm{O}\right)(\mathrm{a}, \mathrm{b})$, $\mathrm{CoB}(\mathrm{MeOH})(\mathrm{c}, \mathrm{d}), \mathrm{CoB}(\mathrm{EtOH})(\mathrm{e}, \mathrm{f})$, and $\mathrm{CoB}(\mathrm{PrOH})(\mathrm{g}, \mathrm{h})$. TEM image insets show corresponding selected area electron diffraction (SAED) patterns.

\subsubsection{SEM and TEM images}

Figure 3 shows SEM and TEM images of the CoB catalysts synthesized in different solvents. SEM images in Fig. 3 show that all samples were composed of densely compacted particles. CoB particles easily agglomerate to reduce the high surface energy derived from their non-crystalline structure. $\mathrm{CoB}\left(\mathrm{H}_{2} \mathrm{O}\right)$ and $\mathrm{CoB}(\mathrm{MeOH})$ particles were relatively small and uniform, while $\mathrm{CoB}(\mathrm{EtOH})$ and $\mathrm{CoB}(\mathrm{PrOH})$ particles were much larger and more agglomerated. TEM images in Fig. 3 show that all samples were composed of many small particles of size 60-150 nm. Although samples had been treated ultrasonically for $20 \mathrm{~min}$, agglomeration was still considerable especially for $\mathrm{CoB}(\mathrm{EtOH})$ and $\mathrm{CoB}(\mathrm{PrOH})$. The inset SAED patterns further confirmed the non-crystalline nature of the CoB catalysts.

\subsection{3. $\quad N_{2}$ sorption measurements}

The $\mathrm{N}_{2}$ adsorption-desorption isotherms and corresponding pore-size distributions of CoB catalysts are shown in Fig. 4. The corresponding properties are summarized in Table 1 . The catalysts exhibited type II isotherms with type H3 hysteresis loops at $p / p_{0}=0.5-0.9$, indicating the presence of mesopores. The pore-size distributions of these samples were relatively wide, with three predominant pore sizes existing at $2.5, \sim 10$, and 

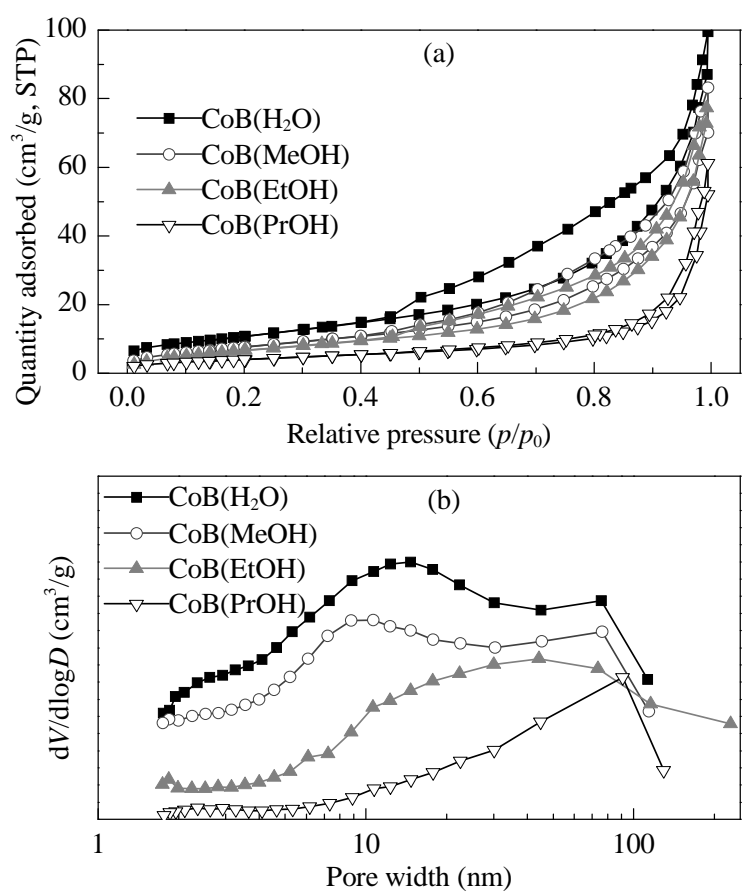

Fig. 4. $\mathrm{N}_{2}$ adsorption-desorption isotherms (a) and average pore-size distributions (b) of CoB catalysts synthesized in different solvents.

$\sim 80 \mathrm{~nm}$. The proportion of 2.5 and $\sim 10 \mathrm{~nm}$ pores decreased following the order: $\mathrm{CoB}\left(\mathrm{H}_{2} \mathrm{O}\right), \mathrm{CoB}(\mathrm{MeOH}), \mathrm{CoB}(\mathrm{EtOH})$, and $\mathrm{CoB}(\mathrm{PrOH})$, while the proportion of $\sim 80 \mathrm{~nm}$ pores increased.
This indicated that solvents affected the textural properties of these catalysts. The hydrolysis of aqueous alkaline $\mathrm{NaBH}_{4}$ by metal-based catalysts generally follows the Schlesinger mechanism [39]. The adsorption and desorption of reactants and products (e.g. $\mathrm{BH}_{4}^{-}, \mathrm{BO}_{2}^{-}$), respectively, and the diffusion process will influence the catalytic properties. Consequently, the surface area, pore size distribution, and pore volume significantly affect catalytic properties.

\subsubsection{XPS analysis}

XPS was used to investigate the elemental composition and states at the surface of CoB catalysts. Figure 5(a) shows XPS survey scan spectra of the CoB catalysts, in which only Co, B, C, and $O$ were observed. The intensity of the $O$ peaks was relatively strong, indicating an oxidized surface during XPS sample preparation. High resolution XPS spectra of the Co and B regions are shown in Fig. 5(b) and (c), respectively. Co $2 p_{3 / 2}$ spectra were fitted with three bands. The band at $778.1 \mathrm{eV}$ was attributed to $\mathrm{Co}^{0}$, and that at $781.0 \mathrm{eV}$ to $\mathrm{CoO}$ or $\mathrm{Co}(\mathrm{OH})_{2}$. The band at $785.4 \mathrm{eV}$ corresponded to the satellite peak of $\mathrm{CoO}$ or $\mathrm{Co}(\mathrm{OH})_{2}$. BE values of the Co species were comparable to standard values $(778.3 \mathrm{eV})$ with almost no shift observed [40]. Numerous oxidation states of Co existed in the sample of each CoB catalyst, probably caused by air oxidation during sample preparation. The B $1 s$ spectra were fitted with two bands, one at $\sim 193.0 \mathrm{eV}$ ascribed to $\mathrm{B}^{3+}$, and another at $\sim 188.5 \mathrm{eV}$ due to elemental $\mathrm{B}^{0}$. The $\mathrm{BE}$ of $\mathrm{B}^{0}$ in $\mathrm{CoB}$ was higher than the standard value $(187.1 \mathrm{eV})$. This was because of electron-donating effects

Table 1

Physicochemical properties of $\mathrm{CoB}$ catalysts synthesized in different solvents.

\begin{tabular}{|c|c|c|c|c|c|c|c|c|c|c|c|c|}
\hline \multirow{2}{*}{ Sample } & \multirow{2}{*}{$\begin{array}{l}\text { BET surface } \\
\text { area }\left(\mathrm{m}^{2} / \mathrm{g}\right)\end{array}$} & \multirow{2}{*}{$\begin{array}{l}\text { Pore volume } \\
\left(\mathrm{cm}^{3} / \mathrm{g}\right)\end{array}$} & \multicolumn{2}{|c|}{ Composition } & \multicolumn{2}{|c|}{$\mathrm{Co}^{0}$} & \multicolumn{2}{|c|}{$\mathrm{Co}^{2+}$} & \multicolumn{2}{|c|}{$\mathrm{B}^{0}$} & \multicolumn{2}{|c|}{$\mathrm{B}^{3+}$} \\
\hline & & & Surface $^{\mathrm{a}}$ & Bulk $^{\mathrm{b}}$ & $\mathrm{BE}(\mathrm{eV})$ & Ratio (\%) & $\mathrm{BE}(\mathrm{eV})$ & Ratio (\%) & $\mathrm{BE}(\mathrm{eV})$ & Ratio (\%) & $\mathrm{BE}(\mathrm{eV})$ & Ratio (\%) \\
\hline $\mathrm{CoB}\left(\mathrm{H}_{2} \mathrm{O}\right)$ & 39 & 0.14 & $\mathrm{Co}_{2.12 \mathrm{~B}}$ & $\mathrm{Co}_{1.93} \mathrm{~B}$ & 778.1 & 31.5 & 781.0 & 68.5 & 188.5 & 41.3 & 193.0 & 58.7 \\
\hline $\mathrm{CoB}(\mathrm{MeOH})$ & 30 & 0.11 & $\mathrm{Co}_{3.05} \mathrm{~B}$ & $\mathrm{Co}_{3.45} \mathrm{~B}$ & 778.2 & 29.8 & 780.9 & 70.2 & 188.5 & 54.6 & 193.0 & 45.4 \\
\hline $\mathrm{CoB}(\mathrm{EtOH})$ & 26 & 0.12 & $\mathrm{Co}_{1.04} \mathrm{~B}$ & $\mathrm{Co}_{0.88} \mathrm{~B}$ & 778.2 & 20.3 & 781.3 & 79.7 & 188.5 & 32.1 & 193.1 & 67.9 \\
\hline $\mathrm{CoB}(\mathrm{PrOH})$ & 15 & 0.08 & $\mathrm{Co}_{0.90 \mathrm{~B}} \mathrm{~B}$ & $\mathrm{Co}_{0.81} \mathrm{~B}$ & 778.5 & 19.6 & 780.8 & 80.4 & 188.5 & 24.8 & 192.9 & 75.2 \\
\hline
\end{tabular}

a Calculated from XPS, molar ratio.

b Calculated from ICP analysis, molar ratio.

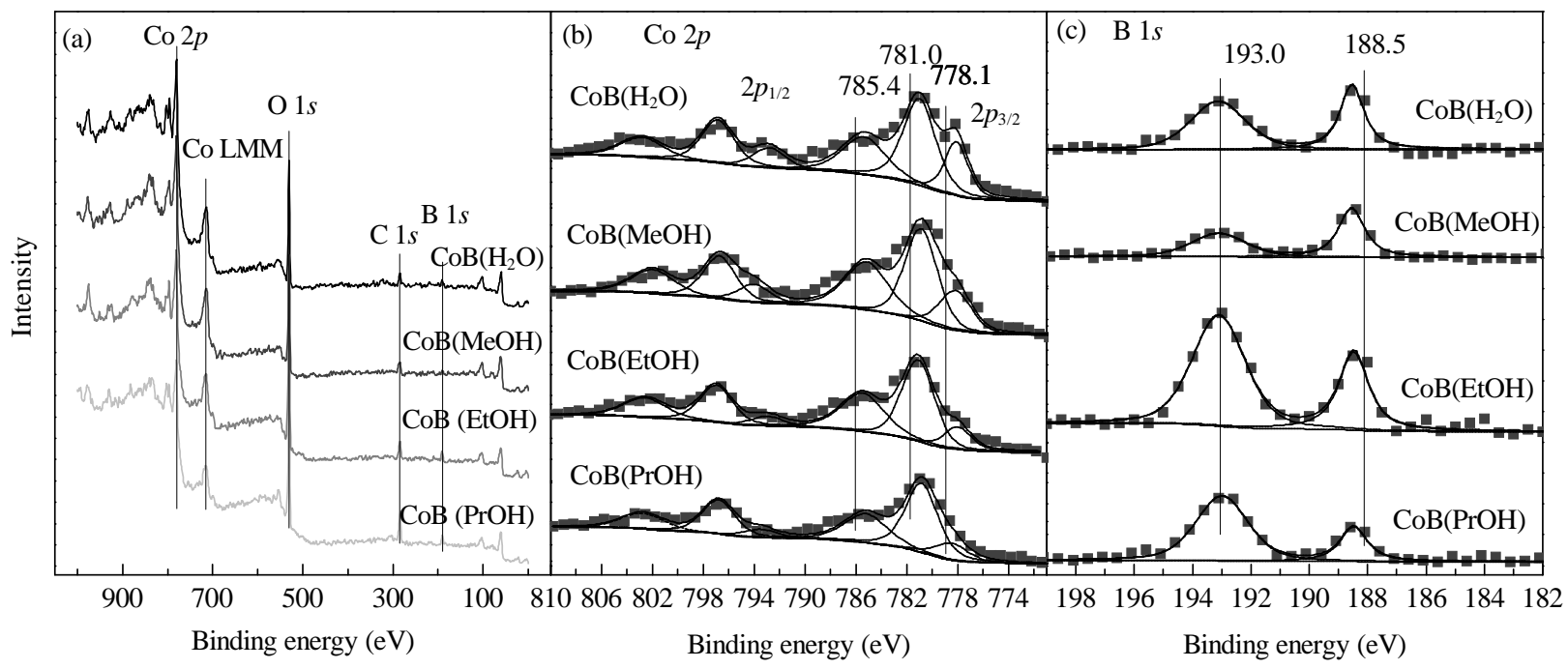

Fig. 5. XPS survey scan (a) and high resolution Co $2 p_{3 / 2}$ (b) and B $1 s$ (c) region spectra of CoB catalysts synthesized in different solvents. 
from $\mathrm{B}^{0}$ to Co species, in agreement with the literature [41-43]. Table 1 summarizes the surface compositions and percentages of Co and B in different chemical states, along with the corresponding $\mathrm{BE}$ values. $\mathrm{BE}$ values of $\mathrm{Co}$ and $\mathrm{B}$ for the $\mathrm{CoB}$ catalysts were all similar, indicating these samples possessed similar electronic states. However, the surface compositions of the CoB catalysts prepared in different solvents differed greatly. Similar results were found in the ICP-AES study (Table 1), and the bulk compositions of $\mathrm{CoB}$ catalysts also varied greatly. Co species on the CoB surface act as active centers for the hydrolysis reaction, so a different $\mathrm{Co} / \mathrm{B}$ ratio affects the catalytic properties.

\subsubsection{UV-Vis absorption measurements}

The electronic state of $\mathrm{Co}^{2+}$ in different solvents has an important effect on the reaction between $\mathrm{Co}^{2+}$ and $\mathrm{BH}_{4}^{-}$, thereby affecting the structure of the resulting CoB catalyst. Figure 6 shows UV-Vis absorption spectra of $\mathrm{Co}^{2+}$ precursor solutions in different solvents, in which a broad band centered on $510 \mathrm{~nm}$ was observed. This absorption was ascribed to $d$ - $d$ transitions of octahedrally coordinated $\mathrm{Co}^{2+}$ by solvent molecules [44-50]. A very weak band centered at $650 \mathrm{~nm}$ was observed in the aqueous $\mathrm{Co}^{2+}$ precursor solution, and corresponded to $d$ - $d$ transitions for tetrahedrally coordinated $\mathrm{Co}^{2+}[44,45]$. This band was not observed in the other three spectra, indicating that $\mathrm{Co}^{2+}$ was mainly octahedrally coordinated in organic solutions. The absorption peak progressively red-shifted from 510.5 to $525.8 \mathrm{~nm}$ with solvent following the order water, methanol, ethanol, $n$-propanol, which corresponded to a decreased $d$ - $d$ transition energy gap. Solvent molecules coordinated with $\mathrm{Co}^{2+}$ through the oxygen atom, which was further connected to $\mathrm{H}, \mathrm{CH}_{3}, \mathrm{C}_{2} \mathrm{H}_{5}$, and $n-\mathrm{C}_{3} \mathrm{H}_{7}$ moieties for water, absolute methanol, ethanol, and $n$-propanol, respectively. The 0 atom electron donating ability increased in the order: $\mathrm{H}<\mathrm{CH}_{3}<$ $\mathrm{C}_{2} \mathrm{H}_{5}<n-\mathrm{C}_{3} \mathrm{H}_{7}$, and a higher electron density of the coordinated atom led to a larger energy gap. Steric hindrance of the coordinated solvent also increased following the same order that decreased the energy gap. These two competing factors resulted in a decreasing energy gap and corresponding red-shift of the absorption peak.

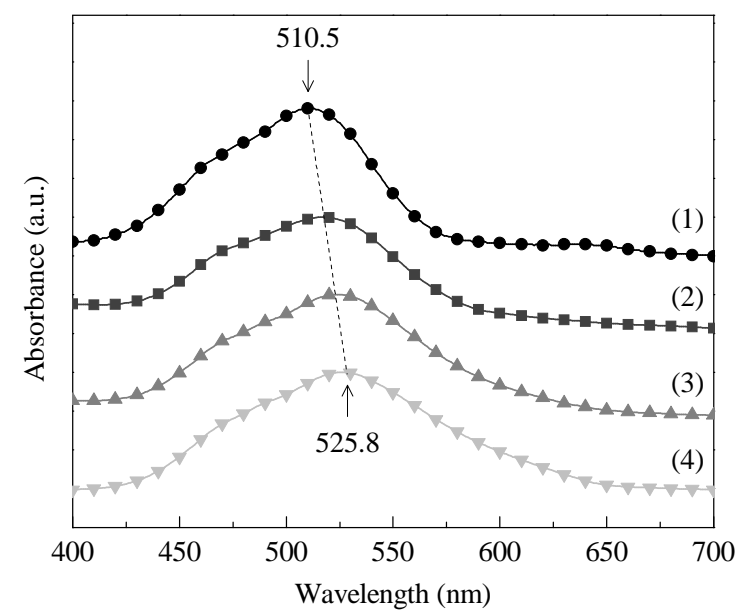

Fig. 6. UV-Vis absorption spectra of $\mathrm{Co}^{2+}$ in water (1), methanol (2), ethanol (3), and $n$-propanol (4).

\subsection{Discussion of solvent effects}

\subsubsection{Solvent effects on the surface composition of $\mathrm{CoB}$ catalysts}

The following reactions occurred in solution during synthesis [46-48]:

$$
\begin{aligned}
& \mathrm{BH}_{4}^{-}+2 \mathrm{Co}^{2+}+4 \mathrm{RO}^{-} \rightarrow \mathrm{B}(\mathrm{OR})_{4}^{-}+2 \mathrm{Co} \downarrow+2 \mathrm{H}_{2} \uparrow \\
& 2 \mathrm{BH}_{4}^{-}+2 \mathrm{ROH} \rightarrow 2 \mathrm{~B} \downarrow+5 \mathrm{H}_{2} \uparrow+2 \mathrm{RO}^{-} \\
& \mathrm{BH}_{4}^{-}+4 \mathrm{ROH} \rightarrow \mathrm{B}(\mathrm{OR})_{4}^{-}+4 \mathrm{H}_{2} \uparrow
\end{aligned}
$$

in which $\mathrm{R}=\mathrm{H}, \mathrm{CH}_{3}, \mathrm{C}_{2} \mathrm{H}_{5}$, and $n-\mathrm{C}_{3} \mathrm{H}_{7}$ when the solvent is water, methanol, ethanol, and $n$-propanol, respectively.

The relative rates of these reactions led to variations of $\mathrm{CoB}$ composition. Reactions (1) and (2) resulted in the formation of elemental Co and B, which in turn formed the $\mathrm{CoB}$ metal boride. Reaction (3) was the solvolysis of $\mathrm{NaBH}_{4}$, which is closely related to the acidity of the solvent and steric hindrance of the $\mathrm{R}$ group. When $\mathrm{BH}_{4}-$ ions encountered solvent molecules, reaction (3) competed with reaction (2). For the $\mathrm{ROH}$ solvents used here, acidity decreased in the order $\mathrm{R}=\mathrm{H}, \mathrm{CH}_{3}, \mathrm{C}_{2} \mathrm{H}_{5}, n-\mathrm{C}_{3} \mathrm{H}_{7}$ because of electron repulsion of the alkyl group. Furthermore, the steric hindrance of the R group increased, so the solvolysis reaction rate decreased following the same order. As a result, the probability of reaction (2) proceeding increased following the order: $\mathrm{R}=\mathrm{H}, \mathrm{CH}_{3}, \mathrm{C}_{2} \mathrm{H}_{5}, n-\mathrm{C}_{3} \mathrm{H}_{7}$, and so the $\mathrm{Co} / \mathrm{B}$ ratio decreased following the same order. Reaction (1) shows that the $\mathrm{Co}^{2+}$ reduction required the participation of $\mathrm{RO}^{-}$, and higher solvent acidity and lower $\mathrm{R}$ group steric hindrance favored reaction (1). This accounts for the $\mathrm{Co} / \mathrm{B}$ ratio of $\mathrm{CoB}(\mathrm{MeOH})$ being larger than that of $\mathrm{CoB}\left(\mathrm{H}_{2} \mathrm{O}\right)$.

\subsubsection{Solvent effects on the structure of CoB catalysts}

Solvent viscosity in addition to polarity also influences the coordination of solvent molecules to $\mathrm{Co}^{2+}$. The precipitation process for $\mathrm{CoB}$ nanoparticles consists of nucleation followed by a particle growth stage [50]. Both the nucleation and growth stages are affected by solvent viscosity, as diffusion is important in both stages. An increase in solvent viscosity will significantly decrease solution species diffusion rates, and cause local concentrated regions for reaction and agglomeration. Thus, increased solvent viscosity would favor increased agglomeration. The viscosity of each solvent is listed in Table 2 [49]. CoB that formed in the low viscosity solvents of methanol and water possessed smaller particle sizes, while $\mathrm{CoB}(\mathrm{EtOH})$ and $\mathrm{CoB}(\mathrm{PrOH})$ had larger particle sizes and were more agglomerated, as shown in SEM and TEM observations.

In summary, the solvent effects on the structure of CoB catalysts are illustrated in Fig. 7. The combination of solvent polarity, steric hindrance, and viscosity resulted in a relatively uniform morphology for $\mathrm{CoB}\left(\mathrm{H}_{2} \mathrm{O}\right)$, $\mathrm{CoB}(\mathrm{MeOH})$, and less uni-

Table 2

Viscosity of solvents at $273 \mathrm{~K}$ [49].

\begin{tabular}{lc}
\hline Solvent & Viscosity $\left((\mathrm{mN} \cdot \mathrm{s}) / \mathrm{m}^{2}\right)$ \\
\hline Water & 1.793 \\
Methanol & 0.793 \\
Ethanol & 1.786 \\
$n$-Propanol & 3.883 \\
\hline
\end{tabular}




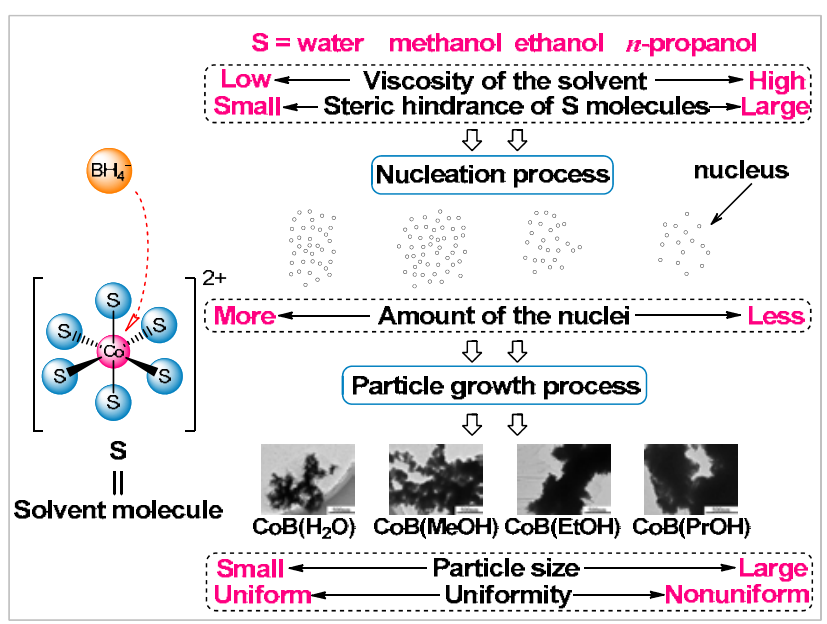

Fig. 7. Illustration showing solvent effects on the structure and morphology of CoB catalysts synthesized in different solvents.

form morphology for $\mathrm{CoB}(\mathrm{EtOH})$ and $\mathrm{CoB}(\mathrm{PrOH})$, which in turn resulted in their different catalytic performance.

\section{Conclusions}

A series of $\mathrm{CoB}$ catalysts were synthesized by chemical reduction in water, absolute methanol, ethanol, and $n$-propanol. Catalysts were evaluated by the hydrolysis of $\mathrm{NaBH}_{4}$ alkaline solution ( $1 \mathrm{wt} \% \mathrm{NaBH}_{4}$ aqueous solution with $5 \mathrm{wt} \% \mathrm{NaOH}$ ) at $293 \mathrm{~K}$, and showed different catalytic activities. Hydrogen generation rates followed the order: $\mathrm{CoB}(\mathrm{MeOH})>\mathrm{CoB}\left(\mathrm{H}_{2} \mathrm{O}\right)>$ $\mathrm{CoB}(\mathrm{EtOH})>\mathrm{CoB}(\mathrm{PrOH})$. XRD and SEAD patterns showed that all $\mathrm{CoB}$ catalysts possessed a non-crystalline structure. FE-SEM and TEM showed that the catalysts were composed of many small particles, and that agglomeration was more pronounced for $\mathrm{CoB}(\mathrm{EtOH})$ and $\mathrm{CoB}(\mathrm{PrOH}) . \mathrm{N}_{2}$ sorption measurements showed that the $\mathrm{CoB}$ catalysts synthesized in different solvents had very different surface areas, pore size distributions and pore volumes. The different morphology and texture properties were key factors for the different catalytic properties of CoB catalysts. XPS measurements showed that Co and B species existed in oxidized and elemental states in the CoB catalysts. Although BE values of each state were similar, their surface compositions varied greatly and $\mathrm{CoB}$ catalysts possessing higher Co/B ratios exhibited better catalytic properties. The solvent acidity, steric hindrance, and viscosity accounted for the solvent effects, and a possible mechanism was proposed. These results improve our understanding of solvent effects during the preparation of non-crystalline catalysts, and help us explore the structure-activity relationship of these catalysts.

\section{References}

[1] Torres D, Llobet S, Pinilla J L, Lázaro M J, Suelves I, Moliner R. J Energy Chem, 2012, 21: 367

[2] Xu D Y, Zhao L, Dai P, Ji S F. J Nat Gas Chem, 2012, 21: 488

[3] Marrero-Alfonso E Y, Beaird A M, Davis T A, Matthews M A. Ind Eng Chem Res, 2009, 48: 3703

[4] Tamura T, Tominaga Y, Matumoto K, Fuda T, Kuriiwa T, Kamega- wa A, Takamura H, Okada M. J Alloys Comp, 2002, 330-332: 522

[5] Rangel C M, Fernandes V R, Slavkov Y, Bozukov L.J Power Sources, 2008, 181: 382

[6] Rangel C M, Fernandes V R, Slavkov Y, Bozukov L. Int J Hydrogen Energy, 2009, 34: 4587

[7] Kunowsky M, Weinberger B, Lamari Darkrim F, Suarez-Garcia F, Cazorala-Amoros D, Linares S. Int J Hydrogen Energy, 2008, 33: 3091

[8] Binwale R B, Rayalu S, Devotta S, Ichikawa M. Int J Hydrogen Energy, 2008, 33: 360

[9] Gross K J, Thomas G J, Jensen C M. J Alloys Comp, 2002, 330-332: 683

[10] Zuttel A, Wenger P, Rensch S, Sudan P, Mauron P, Emmenegger C.J Power Sources, 2003, 118: 1

[11] Eberle U, Felderhoff M, Schuth F. Angew Chem, Int Ed, 2009, 48: 6608

[12] Bakkar S. Int J Hydrogen Energy, 2010, 35: 6784

[13] Zhang J S, Fisher T S, Gore J P, Hazra D, Ramachandran P V. Int J Hydrogen Energy, 2006, 31: 2292

[14] Kojima Y, Suzuki K, Fukumoto K, Sasaki M, Yamamoto T, Kawai Y, Hayashi H. Int J Hydrogen Energy, 2002, 27: 1029

[15] Kojima Y, Suzuki K, Fukumoto K, Kawai Y, Kimbara M, Nakanishi H, Matsumoto S. J Power Sources, 2004, 125: 22

[16] Demirci U B, Garin F. J Alloys Comp, 2008, 463: 107

[17] Liu B H, Li Z P, Suda S. J Alloys Comp, 2006, 415: 288

[18] Jeong S U, Cho E A, Nam S W, Oh I H, Jung U H, Kim S H. Int J Hydrogen Energy, 2007, 32: 1749

[19] Ingersoll J C, Mani N, Thenmozhiyal J C, Muthaiah A. J Power Sources, 2007, 173: 450

[20] Lee J, Kong K Y, Jung C R, Cho E, Yoon S P, Han J, Lee T G, Nam S W. Catal Today, 2007, 120: 305

[21] Ding W P, Guo X F, Mo M, Zhu Y, Chen Y. Chin J Catal (丁维平, 郭学 锋, 莫敏, 祝艳, 陈懿. 催化学报), 2010, 26: 887

[22] Yao K W, Fan Y N, Chen Y, Li X Sh. Chin J Catal (姚凯文, 范以宁, 陈 懿, 李新生. 催化学报), 1995, 16: 253

[23] Yao K W, Fan Y N, Kuang W X, Chen Y. Acta Phys-Chim Sin (姚凯文, 范以宁, 匡文兴, 陈懿. 物理化学学报), 1996, 12: 954

[24] Liu B H, Li Q. Int J Hydrogen Energy, 2008, 33: 7385

[25] Zhu Z H, Ma Jinqiang, Xu L, Xu L, Li H X, Liu H. ACS Catal, 2012, 2: 2119

[26] Li H, Liu J, Xie S H, Qiao M H, Dai W L, Li H X. J Catal, 2008, 259: 104

[27] Pei Y, Guo P J, Qiao M H, Li H X, Wei S Q, He H Y, Fan K N. J Catal, 2007, 248: 303

[28] Pei Y, Zhou G B, Luan N, Zong B N, Qiao M H, Tao F. Chem Soc Rev, 2012, 41: 8140

[29] Shen B R, Fang Zh G, Fang K N, Deng J F. Acta Chim Sin (沈百荣, 方 志刚, 范康年, 邓景发. 化学学报), 1999, 57: 366

[30] Fang Z G, Shen B R, Lu J, Fang K N, Deng J F. Acta Chim Sin (方志刚, 沈百荣, 陆靖, 范康年, 邓景发. 化学学报), 1999, 57: 894

[31] Zong B N, Min E Z, Zhu Y S (宗保宁, 闵恩泽, 朱永山). CN Patent 1073726. 1993

[32] Mu X H, Zong B N, Min E Z. US Patent 6368996. 2002

[33] Retnamma R, Novais A Q Rangel C M. Int J Hydrogen Energy, 2011, 36: 9772

[34] Liu B H, Li Z P. J Power Sources, 2009, 187: 527

[35] Liu Y C, Huang C Y, Chen Y W. Ind Eng Chem Res, 2006, 45: 62

[36] Fan G Y, Zhang Y, Zhou Y F, Li R X, Chen H, Li X J. Chem Lett, 2008, 37: 852

[37] Ning J B, Xu J, Liu J, Miao H, Ma H, Chen C, Li X Q, Zhou L P, Yu W Q. Catal Commun, 2007, 8: 1763

[38] Liu H, Deng J, Li W. Catal Lett, 2010, 137: 261 


\title{
Graphical Abstract
}

Chin. J. Catal., 2013, 34: 979-985 doi: 10.1016/S1872-2067(12)60577-4

Solvent effects in the synthesis of CoB catalysts on hydrogen generation from hydrolysis of sodium borohydride

SHEN Xiaochen, DAI Min, GAO Ming, ZHAO Bin*, DING Weiping Nanjing University

Solvent effects in the synthesis of non-crystalline CoB catalysts on the structures, morphologies, and catalytic properties were studied. A possible mechanism was proposed.

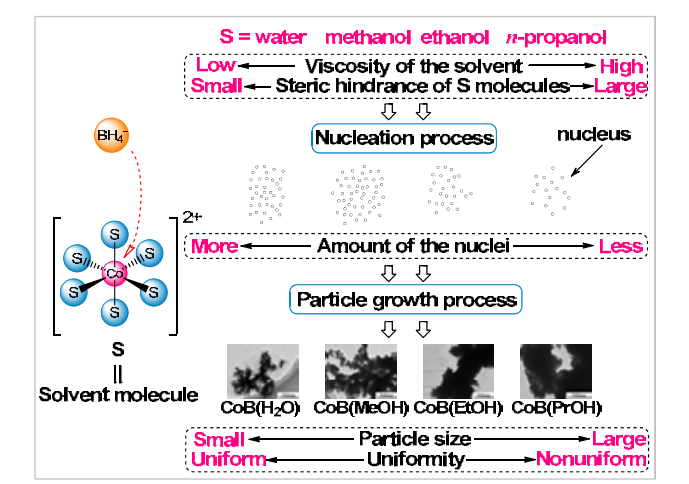

[39] Schlesinger H I, Brown H C, Finholt A B, Gilbreath J R, Hockstra H R, Hydo E K. J Am Chem Soc, 1953, 75: 215

[40] Moulder J F, Stickle W F, Sobol P E, Bomben K D. Handbook of X-Ray Photoelectron Spectroscopy. Eden Prairie: Physical Electronics Inc, 1995. 38

[41] Liu Y C, Chen Y W. Ind Eng Chem Res, 2006, 45: 2973

[42] Dai W L, Qiao M H, Deng J F. Appl Surf Sci, 1997, 120: 119

[43] Deng J F, Yang J, Sheng S S, Chen H G, Xiong G X. J Catal, 1994, 150: 434

[44] Vraneš M, Gadžurić S B, Zsigrai I J, Dožić S. J Mol Liquids, 2010, 152: 34
[45] Pokutsa A, Zaborovskiy A, Maksym D, Muzart J, Makitra R, Pal'chykova O. React Kinet Mechan Catal, 2010, 100: 309

[46] Glavee G N, Klabunde K J, Sorensen C M, Hadjapanayis G C. Langmuir, 1992, 8: 771

[47] Glavee G N, Klabunde K J, Sorensen C M, Hadjapanayis G C. Langmuir, 1993, 9: 162

[48] Chen Y. Catal Today, 1998, 44: 3

[49] Dean J A. Lange's Handbook of Chemistry. 15th Ed. New York: McGraw-Hill, 1999

[50] Wang Z L, Liu Y, Zhang Z. Handbook of Nanophase and Nanostructured Materials. New York: Kluwer Academic, 2003

\section{CoB催化剂制备中的溶剂效应及催化硼氢化钠水解产氢的性能}

\author{
沈晓晨, 戴 敏, 高鸣, 赵 斌, 丁维平 \\ 南京大学化学化工学院介观化学教育部重点实验室, 江苏南京 210093
}

摘要: 分别以不同粘度和极性的水、甲醇、乙醇、正丙醇为溶剂制备了钴硼催化剂, 并通过X射线衍射、场发射扫描电镜、透射 电镜、X射线光电子能谱和 $\mathrm{N}_{2}$ 吸附等表征手段对溶剂效应进行了深入探索. 所制备的钴喼催化剂具有非晶结构, 且随着溶剂粘度 的增加, 粒子团聚现象加剧. 不同溶剂中制备的钴嗍催化剂对于硼氢化钠水解产氢反应的活性具有显著差异, XPS测试表明钴元 素和嗍元素均以元素态及氧化态形式存在, 而且不同溶剂中制备的钴嗍催化剂具有不同的表面钴/嗍比, 具有高钴/嗍比的催化剂 有更好的催化性能. 从溶剂的粘度、溶剂分子的空间位阻效应等方面对溶剂效应进行了分析, 并提出了钴硼催化剂在不同溶剂中 可能的形成机理.

关键词: 嗍氢化钠; 水解; 产氢; 钴嗍; 非晶结构; 溶剂效应

收稿日期: 2013-01-11. 接受日期: 2013-03-08. 出版日期: 2013-05-20.

*通讯联系人. 电话: (025)83592304; 传真: (025)83317761; 电子信箱: binzhao@nju.edu.cn

基金来源: 江苏省自然科学基金(BK2010387); 国家自然科学基金(41172239); 中央高校基本科研业务费专项资金(1118020513, 1106020513).

本文的英文电子版由Elsevier出版社在ScienceDirect上出版(http://www.sciencedirect.com/science/journal/18722067). 